\title{
Non-invasive assessment of perioperative myocardial cell damage by circulating cardiac troponin $\mathrm{T}$
}

Hugo A Katus, Michael Schoeppenthau, Ahmed Tanzeem, Hans G Bauer, Werner Saggau, Klaus W Diederich, Siegfried Hagl, Wolfgang Kuebler

\section{Abstract}

Troponin $T$ is a unique cardiac antigen which is continuously released from infarcting myocardium. Its cardiospecificity as a marker protein might be particularly useful in assessing myocardial cell damage in patients undergoing cardiac surgery. Therefore, circulating troponin $T$ was measured in serial blood samples from 56 patients undergoing cardiac surgery and in two control groups - 22 patients undergoing minor orthopaedic surgery and 12 patients undergoing lung surgery by median sternotomy. In both control groups no troponin $T$ could be detected, whereas activities of creatine kinase were raised in all 12 lung surgery controls and activities of the $M B$ isoenzyme were raised in five of the 12 patients in the lung surgery group and in four of the 22 patients in the orthopaedic surgery group, respectively. All the patients undergoing coronary artery bypass grafting $(n=47)$ and cardiac surgery for other reasons $(n=9)$ had detectable concentrations of troponin $T$. Five patients had perioperative myocardial infarction detected as new $Q$ waves and $R$ wave reductions. In these five patients troponin $T$ release persisted and serum concentrations $(5 \cdot 5-23 \mu \mathrm{g} / 1)$ reached a peak on the fourth postoperative day. In the 51 patients without perioperative myocardial infarction serum concentrations and the release kinetics of troponin $T$ depended on the duration of cardiac arrest. In patients in whom aortic cross clamping was short troponin $T$ increased slightly on the first postoperative days; in patients with longer periods of aortic cross clamping troponin $T$ concentrations were higher and remained so beyond the fifth postoperative day. In patients with non-specific changes on the electrocardiogram troponin $T$ concentrations were significantly higher on days 1 and 4 after operation than in patients with normal postoperative electrocardiograms $(11.2(5)$ and $4.5(2.6) v 8.2(3.4)$ and $2.9(1.6) \mu \mathrm{g} / 1)$.

Serum concentrations of troponin $T$ showed some myocardial cell damage in every patient undergoing cardiac surgery. The persistent increases that were more common in patients with longer periods of cardiac arrest must have been caused by damage to the contractile apparatus. These results suggest that perioperative myocardial cell necrosis may be more common than indicated by changes of the QRS complex on the electrocardiogram.

Measurements of serum creatine kinase (EC 2.7.3.2) and lactate dehydrogenase (EC 1.1.1.27) activity and changes on the electrocardiogram are reliable indicators of acute myocardial infarction if there is no major damage to skeletal muscle. In patients undergoing cardiac surgery the value of these diagnostic methods is limited by enzyme release from non-cardiac tissues and nonspecific changes (for example, ST segment and $T$ wave) on the electrocardiogram. ${ }^{12}$ Consequently, only major perioperative acute myocardial infarctions can be confirmed by these diagnostic methods. ${ }^{34}$

The specificity of serological testing for perioperative acute myocardial infarction can be improved by measuring the $\mathrm{MB}$ isoform of creatine kinase, but even creatine kinase $\mathrm{MB}$ is not a cardiospecific molecule $e^{5-7}$ and some of the circulating creatine kinase $\mathrm{MB}$, which is consistently found in patients undergoing cardiac surgery, ${ }^{89}$ might well originate from non-cardiac tissues. Limited specificity hampers the assessment of the effectiveness of various cardioprotective measures.

Different protein isoforms in muscles can be identified by immunoassay. ${ }^{10-12}$ Proteins derived from the contractile apparatus are released in patients with acute myocardial infarction and in some patients with unstable angina. ${ }^{13-17}$ Sensitive assays that detect minor myocardial cell damage with high sensitivity and specificity would be especially useful in patients with concomitant damage to the skeletal muscle which is inevitable during cardiac surgery. We have measured circulating cardiac troponin $T$ in patients undergoing cardiac sụrgery.

\section{Patients and methods}

PATIENTS

The first control group consisted of 22 patients with fractures of forearm, hand, shank, and foot admitted during a two week interval to an orthopaedic surgery ward (table). Skeletal muscle damage in this group was minor and resembled that in patients undergoing median 
Clinical characteristics (mean (SD)) of the study groups

\begin{tabular}{|c|c|c|c|c|c|c|c|}
\hline \multirow[b]{2}{*}{ Study group } & \multirow[b]{2}{*}{ No } & \multirow[b]{2}{*}{ Age (yr) } & \multicolumn{2}{|c|}{ Sex } & \multicolumn{3}{|c|}{ Duration (min) of: } \\
\hline & & & $M$ & $F$ & Operation & Extracorporeal perfusion & Cross clamping \\
\hline $\begin{array}{l}\text { Orthopaedic surgery } \\
\text { Thoracic non-cardiac } \\
\text { Cardiac surgery (coronary) } \\
\text { Cardiac surgery (non-coronary) }\end{array}$ & $\begin{array}{r}22 \\
12 \\
47 \\
9\end{array}$ & $\begin{array}{l}47(18) \\
46(17) \\
59(8) \\
44(17)\end{array}$ & $\begin{array}{r}13 \\
12 \\
37 \\
5\end{array}$ & $\begin{array}{r}9 \\
0 \\
10 \\
4\end{array}$ & $\begin{array}{r}29(21) \\
135(54) \\
190(42) \\
158(42)\end{array}$ & $\begin{array}{l}- \\
\overline{83}(40) \\
88(34)\end{array}$ & $\begin{array}{l}- \\
\overline{55}(27) \\
65(25)\end{array}$ \\
\hline
\end{tabular}

sternotomy. In this group of otherwise healthy patients we took blood samples on two consecutive days after operation.

The second control group consisted of 12 men undergoing median sternotomy for resection of mediastinal tumour or of solitary pulmonary metastasis (table). In three patients additional pericardectomy had to be performed; this was accomplished without major trauma to the heart. There was no evidence of important coronary artery disease in these patients as assessed by history, electrocardiogram, and preoperative exercise stress testing. After thoracic surgery there were no signs of myocardial ischaemia on the 12 lead electrocardiogram immediately after and six hours after operation. In this group of patients $10 \mathrm{ml}$ blood was taken before and two, 16, 40, 64 , and 88 hours after thoracotomy.

The coronary artery bypass graft group consisted of 37 men and 10 women (mean age 59 years) (table). At the time of coronary angiography 30 patients $(64 \%)$ complained of unstable angina; this was stabilised by medical treatment in 21 patients before operation. The remaining $17(36 \%)$ patients had stable angina. Left ventricular function was normal in 24 $(51 \%)$ patients, impaired in $16(34 \%)$ patients, and poor in seven $(15 \%)$ patients. Previous myocardial infarction was found in $26(49 \%)$, diabetes in $15(29 \%)$, and impaired renal function in nine $(10 \%)$ of the 47 patients. Coronary angiography showed one vessel disease in three $(6 \%)$ patients, two vessel disease in eight $(17 \%)$ patients, and three vessel disease in $36(77 \%)$ patients. A mean of three bypass grafts per patient was implanted. The internal mammary artery was used as the bypass vessel in 27 patients. The mean durations of operation, of extracorporeal perfusion, and of aortic cross clamping were 190,83 , and 55 minutes, respectively. Two patients needed postoperative intra-aortic balloon counterpulsation.

The patient group with cardiac surgery other than coronary artery bypass grafting consisted of two patients with patch closure of an atrial septal defect, six patients with aortic valve replacement, and one patient with mitral valve replacement. The mean age of the four women and five men was 46 years (table). The mean durations of cardiac surgery, of extracorporeal perfusion, and of aortic cross clamping were 158,88 , and 65 minutes, respectively. Cardioprotection was achieved by infusion of a mean of 1.61 Bretschneider HTK cardioplegic solution (sodium chloride $15 \mathrm{mmol} / \mathrm{l}$, potassium chloride $9 \mathrm{mmol} / \mathrm{l}$, potassium ketoglutarate 1 $\mathrm{mmol} / \mathrm{l}$, magnesium chloride $4 \mathrm{mmol} / \mathrm{l}$, histidine $198 \mathrm{mmol} / \mathrm{l}$, tryptophan $2.0 \mathrm{mmol} / \mathrm{l}$, mannitol $30 \mathrm{mmol} / 1, \mathrm{pH} 7 \cdot 1$, osmolality $=310$ mosmol/1), ${ }^{18}$ at $4^{\circ} \mathrm{C}$ into the aortic root. The heart was cooled externally by $4^{\circ} \mathrm{C}$ sodium chloride solution, to a mean myocardial temperature of $10.5^{\circ} \mathrm{C}$. The body temperature was kept at $26^{\circ} \mathrm{C}$ by systemic hypothermia. Left atrial venting of the heart was routinely performed.

All patients gave informed consent to the study after thorough explanation of the protocol. The investigation was approved by the ethics committee on human research.

MEASUREMENTS OF CARDIAC MARKER PROTEINS We collected $10 \mathrm{ml}$ of blood before the operation; at the beginning and the end of extracorporeal perfusion; at the end of operation; 2 , 8,12 , and 24 hours after surgery; and then once daily until the sixth postoperative day. The blood samples were stored at room temperature for 30 minutes to allow clotting. After centrifugation the serum was stored at $-20^{\circ} \mathrm{C}$ until all blood samples had been collected.

Cardiac troponin $T$ was measured by an enzyme immunoassay developed in cooperation with Boehringer Mannheim. ${ }^{17}$ In this assay the troponin $T$ molecule is bound by an affinitypurified cardiospecific sheep anti-troponin $T$ antibody fraction immobilised on test tubes. Troponin $T$ bound to the test tubes by these antibodies is then detected by the addition of a monoclonal anti-troponin $\mathrm{T}$ antibody labelled with horseradish peroxidase. This peroxidase labelled second antibody binds to the troponin $\mathrm{T}$ molecule on its specific epitope. The peroxidase activity adhering to the assay tubes after several steps of washing is assessed by colorimetric measurement of substrate conversion.

The troponin $\mathrm{T}$ measurements were performed in duplicate by a batch ELISA analyser (Enzymun Test System ES 22, Boehringer Mannheim). In this system $200 \mu \mathrm{l}$ of the patient's serum sample was added to the test tubes; the addition of $1 \mathrm{ml}$ peroxidase labelled monoclonal anti-troponin $T$ antibody and all washing steps were performed semiautomatically. The test results were obtained in 90 minutes. The assay detected from 0.5 to 18 $\mu \mathrm{g} / 1$ with inter-day coefficients of variation ranging from 5.0 to $7.0 \%$ (fig 1 ). The analytical sensitivity of this test was determined as the mean value +3 SD of non-specific colour change in the test tubes containing $5 \%$ bovine serum albumin buffer solutions. The background colour change under these conditions was equivalent to $0.25(0.11) \mu \mathrm{g} / 1$ of troponin $\mathrm{T}$. The mean substrate conversion in 126 healthy volunteers and a pool of blood donors was equivalent to $0 \cdot 18(0 \cdot 1) \mu \mathrm{g} / 1$ of troponin 
Figure 1 Mean (1 SD) of all 10 standard curves of the cardiac troponin $T$ test performed on different days during the study. The coefficients of variation are indicated as percentage values at each protein standard concentration.

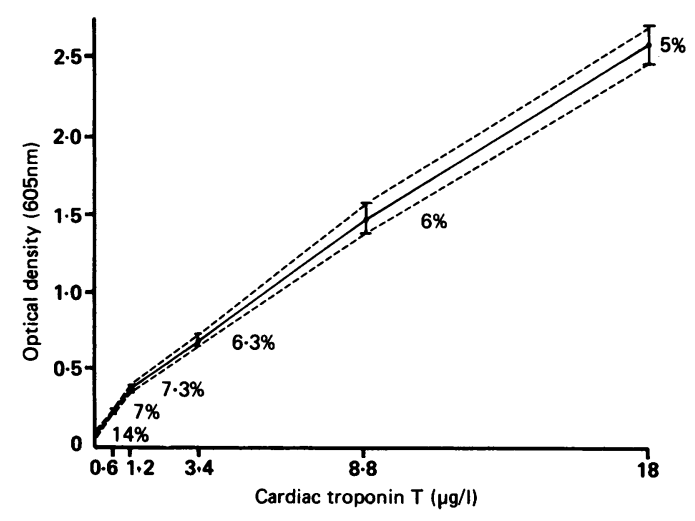

T. ${ }^{19}$ Thus in normal human serum no circulating troponin $T$ was found at the sensitivity limit of this assay because non-specific binding and the imprecision of the test precluded a quantitative analysis of troponin $T$ concentrations below $0.5 \mu \mathrm{g} / \mathrm{l}$. In the present study the test result of sera below $0.5 \mu \mathrm{g} / 1$ was recorded as "not increased" and the results of the measurements were given.

Screening assays and immunoblot analysis showed that the affinity-purified antibodies only reacted with cardiac troponin $T$. However, because of non-specific absorption of purified skeletal troponin $\mathrm{T}$ to the assay tubes there was a $1-2 \%$ cross reactivity with troponin $T$ extracted from mixed human skeletal muscle.

We measured total serum creatine kinase activity in a Chem 1 analyser (Technicon, Terrytown, USA) using the reagents provided by the manufacturer. We used an immunoinhibition assay for creatine kinase $\mathrm{MB} .^{20}$ The upper limit of the normal range at $25^{\circ} \mathrm{C}$ was 75 IU/1 for total creatine kinase and $10 \mathrm{IU} / 1$ for creatine kinase $\mathrm{MB}$.

\section{ELECTROCARDIOGRAM}

A 12 lead electrocardiogram was obtained before operation; 2,6 , and 48 hours after operation; and then once on the seventh postoperative day. Diagnostic criteria for perioperative acute myocardial infarction were new $Q$ waves of $>0.04 \mathrm{~ms}$ and reductions in the $\mathrm{R}$ wave of $>25 \%$ in at least two leads of the 12 lead electrocardiogram on day 7. Newly detected conduction defects and changes in the ST segment, $T$ wave, or $Q R S$ complex not diagnostic for acute myocardial infarction were regarded as non-specific. The electrocardiogram was analysed by an experienced cardiologist (KWD) who was unaware of the serological test results.

\section{STATISTICAL ANALYSIS}

Linear regression analysis and analysis of variance was used throughout the study. Statistical significance was set at the $5 \%$ probability level. The table gives mean values and their standard deviation. The changes in the serum concentration of cardiac troponin $\mathrm{T}$ are shown as medians and interquartile ranges (25-75\%).

\section{Results}

RELEASE OF MARKER PROTEIN IN THE STUDY GROUPS

Figure 2 shows the peak serum concentrations of troponin $\mathrm{T}$ and total creatine kinase activity in the 22 patients who had minor orthopaedic surgery, 12 patients who had lung surgery by median sternotomy, 51 patients with cardiac surgery, and five patients with cardiac surgery and perioperative acute myocardial infarction. Cardiac troponin $\mathrm{T}$ was undetectable in the patients in both control groups (median colour change of substrate solution corresponding to $0.18 \mu \mathrm{g} / 1$ and $0.21 \mu \mathrm{g} / 1$ troponin $\mathrm{T})$. In patients who had cardiac surgery serum concentration of troponin $\mathrm{T}$ was at least twice the analytical sensitivity of the assay (median $5 \mu \mathrm{g} / \mathrm{l}$, range $1 \cdot 3-11 \mu \mathrm{g} / 1)$. The troponin $\mathrm{T}$ concentrations were significantly higher in the patients with electrocardiographic signs of perioperative acute myocardial infarction (median $11 \mu \mathrm{g} / \mathrm{l}$, range $6-31 \mu \mathrm{g} / \mathrm{l})$ than in the cardiac surgery group without acute myocardial infarction ( $p$ $<0.01$ ).

We measured total serum creatine kinase activity to indicate the extent of skeletal muscle damage in the same group of patients. Total serum creatine kinase activity was increased in all but five patients in the control groups and in all 56 cardiac surgery patients. Peak serum creatine kinase activity was significantly higher in the patients with perioperative acute myocardial infarction (median $600 \mathrm{IU} / 1$, range $370-1600 \mathrm{IU} / 1)$ than in the control groups and in the remaining patients who had cardiac surgery. Measurements of serum creatine kinase $M B$ activity gave four and five false positive test results in the groups who had orthopaedic and lung surgery, respectively. Creatine kinase $\mathrm{MB}$ was increased in all but one patient in the cardiac surgery group (median 22

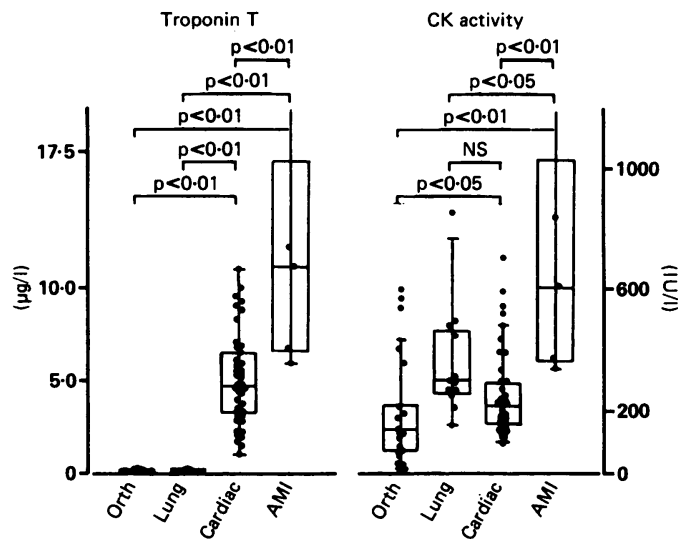

Figure 2 Peak concentrations of cardiac troponin $T$ and peak serum creatine kinase activities in 22 patients who had minor orthopaedic operations, 12 patients who had lung surgery and median sternotomy, 51 patients who had cardiac surgery, and five patients who had cardiac surgery and perioperative acute myocardial infarction. The analytical sensitivity of the troponin $T$ test and the upper limit of normal creatine kinase activity are $0.5 \mu \mathrm{g} / \mathrm{l}$ and $75 I U / l$, respectively. AMI, cardiac surgery group with perioperative myocardial infarction; Cardiac, group that had cardiac surgery without perioperative myocardial infarction; Lung, lung surgery group (median sternotomy); Orth, orthopaedic surgery group. 
$\mathrm{IU} / 1$, range 8-47 IU/1) and in all patients with perioperative acute myocardial infarction (median $70 \mathrm{IU} / 1$, range $21-231 \mathrm{IU} / 1$ ).

CHANGES IN THE SERUM CONCENTRATION OF TROPONIN T IN THE 56 PATIENTS IN THE CARDIAC SURGERY GROUP

Figure 3 shows the 51 patients who had cardiac surgery without perioperative acute myocardial infarction ranked according to their aortic cross clamp time. The three ranked groups show the effects of duration of cardiac arrest on the release kinetics of troponin $T$. Serum troponin $\mathrm{T}$ was increased immediately after surgery, peaked on the first postoperative day, and declined slowly thereafter. The serum concentration of troponin $\mathrm{T}$, and the length of time it was increased, increased with the duration of aortic cross clamping.

In the five patients with perioperative acute myocardial infarction (figure 3 , lower part) troponin $\mathrm{T}$ concentration remained high (up to 20 times the analytical sensitivity of the test) on day 5 after operation. Troponin $T$ concentrations reached a peak $(11 \mu \mathrm{g} / 1)($ range $6-31 \mu \mathrm{g} / 1)$ on the first postoperative day and remained high with a second less well defined peak of 8.4 $\mu \mathrm{g} / 1$ (range $5 \cdot 5-23 \mu \mathrm{g} / \mathrm{l}$ ) on the fourth day after operation.

\section{EFFECTS OF DURATION OF CARDIAC ARREST ON} RELEASE OF TROPONIN T

Both the peak troponin $T$ concentration on days 1 and 4 and cumulative release of troponin $T$, assessed as area under the serum concentration curve, were associated with the duration of cardiac arrest $(\mathrm{p}<0.001, \mathrm{p}<0.01$, and $\mathrm{p}<$ 0.001 , respectively) (fig 4). The duration of extracorporeal perfusion ( $p<0.005, p<0.01$, and $p<0.01$ ) and number of grafts implanted ( $p<0.05$, NS, and $p<0.05$ ) were less strongly related to peak concentrations of troponin $T$ on days 1 and 4 and total troponin $T$ release after operation. Patients with preoperative symptoms of unstable or stable angina had similar perioperative concentrations of troponin $T$.

\section{TROPONIN T RELEASE AND CHANGES ON THE} ELECTROCARDIOGRAM

Figure 5 shows the peak serum concentrations of troponin $T$ on days 1 and 4 and total troponin $T$ release and the accompanying changes on the electrocardiogram in the 51 patients without perioperative acute myocardial infarction. Concentrations of troponin $T$ tended to be higher in the patients with nonspecific changes on the electrocardiogram after operation.

\section{Discussion}

The detection and measurement of minor perioperative myocardial cell necrosis are indicators of the efficiency of cardioprotective measures and operative techniques. Diagnostic methods applied for the detection of acute myocardial infarction in a general hospital population cannot be used to identify minor myocardial cell damage in patients undergoing cardiovascular surgery. In patients undergoing cardiovascular surgery the electrocardiogram is

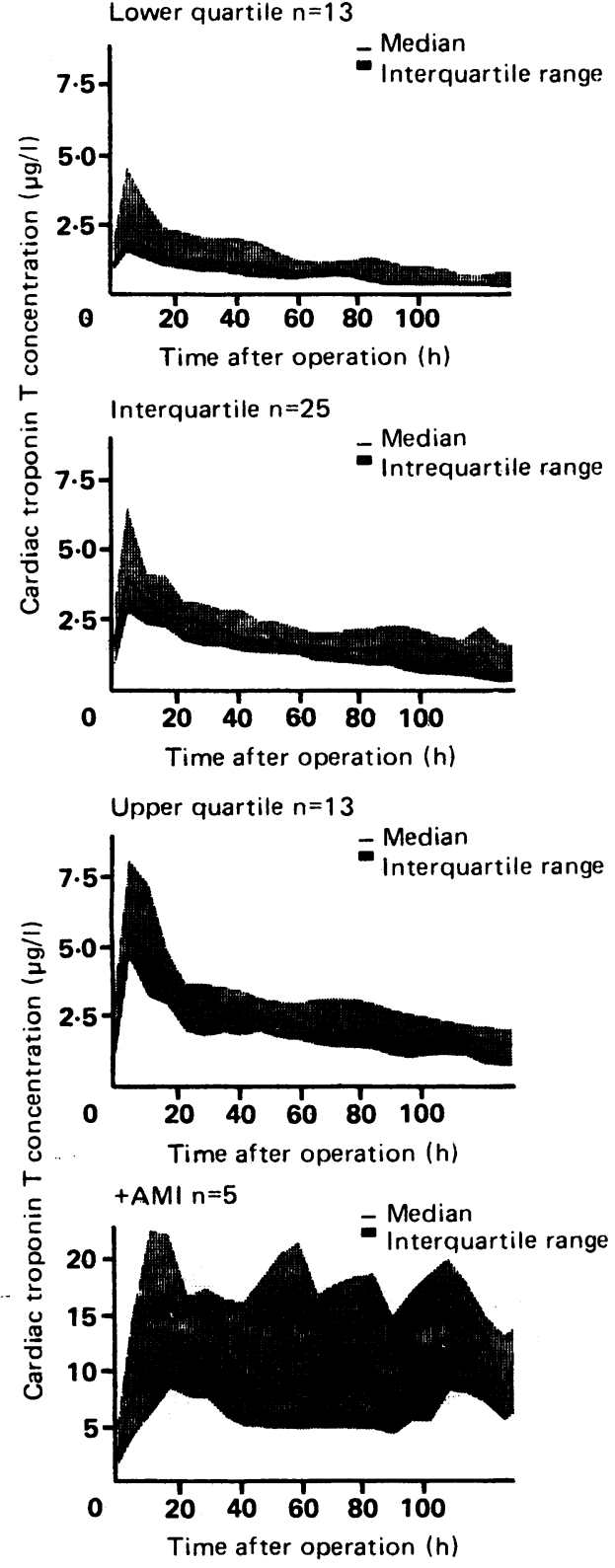

Figure 3 Median and interquartile range of changes in serum concentration of cardiac troponin $T$ in patients who had cardiac surgery, showing its dependency on aortic cross clamping time. The patients are ranked according to their aortic cross clamping time: lower quartile $(<25 \%)$ interquartile, and upper quartile ( $>75 \%)$. The changes in serum concentration in patients with cardiac surgery and perioperative myocardial infarction $(+A M I)$ are also shown (note the different scale for troponin $T$ values).

only useful for detecting major acute myocardial infarction, and even in this subgroup of patients the electrocardiogram is of low sensitivity. ${ }^{21}$ Electrocardiographic changes such as conduction disturbances or changes of the ST segment or $\mathrm{T}$ wave may be caused by minor or diffusely distributed ischaemic cell damage, but these changes are non-specific and cannot be used to evaluate the quality of cardioprotection.

Release of myocardial cell constituents is a common sequela of severe ischaemia, and detection of these cardiac molecules in circulation by quantitative assays indicates the extent of myocardial cell damage independently of its location and distribution within the heart. Yet 
Figure 4 Dependency of troponin $T$ peak values and cumulative release on aortic cross clamp time. Patients with perioperative acute myocardial infarction are excluded.
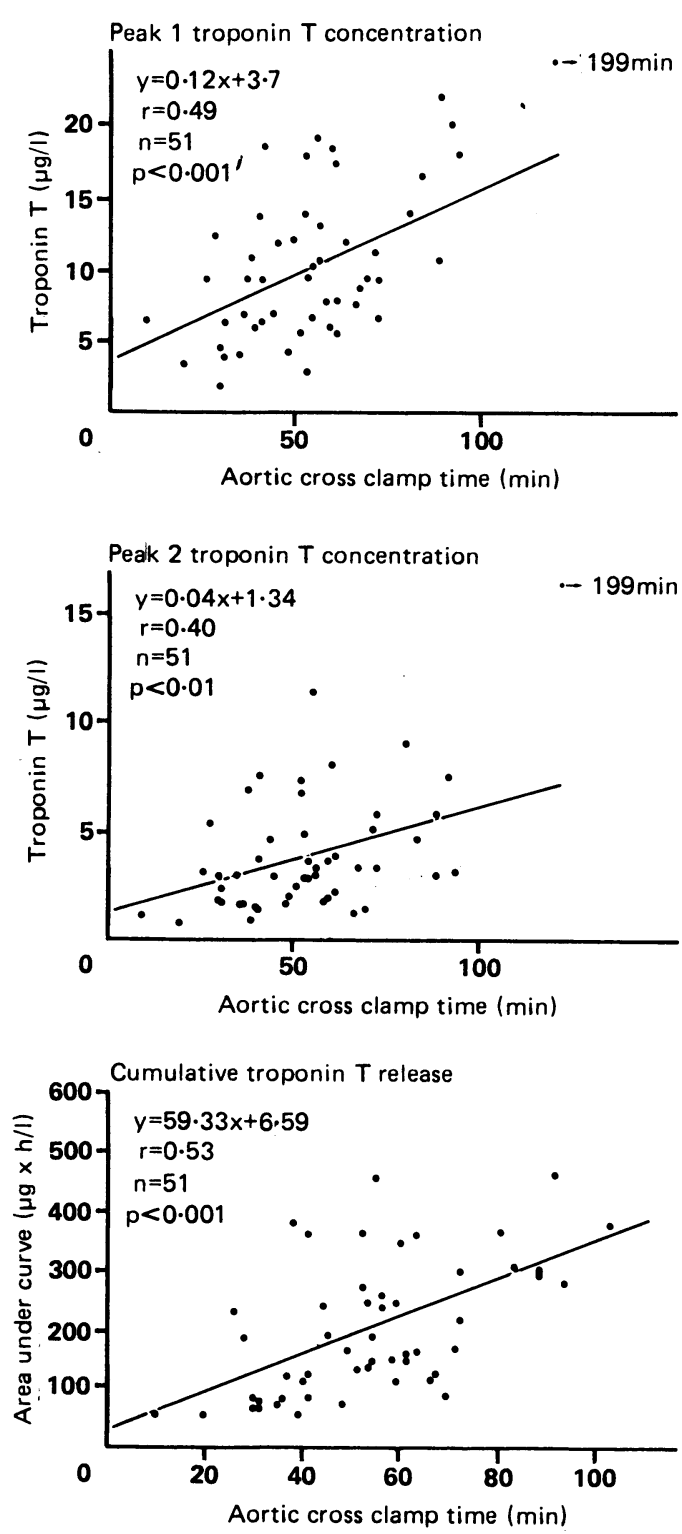

the marker proteins for perioperative cardiac muscle damage must be cardiospecific and should distinguish between reversible and irreversible cell damage. Some circulating creatine kinase $\mathrm{MB}$ activity found perioperatively $^{822-24}$ may originate from concomitant skeletal muscle damage. In addition, there is experimental evidence that cytosolic proteins such as creatine kinase $\mathrm{MB}$, but not subcellularly compartmented molecules, can be released from anoxic but still viable myocytes. ${ }^{25}$ Circulating creatine kinase MB does not always indicate irreversible myocardial cell necrosis.

Troponin $T$ has a cardiospecific molecule with a distinctly different primary structure from its skeletal muscle isoform. ${ }^{11}$ We used affinity purified polyclonal antibodies to distinguish between the cardiac and skeletal muscle isoforms of troponin $\mathrm{T}$. The cross reactivity of $1-2 \%$ with troponin $\mathrm{T}$ extracted from skeletal muscle that we saw in the enzyme immunoassay resulted from non-specific absorption of purified skeletal troponin $\mathrm{T}$ on to the assay tubes. Because troponin $T$ was not detectable in patients with skeletal muscle damage and creatine kinase activities up to $50000 \mathrm{IU} /$ $1,{ }^{19}$ it may be that minor modifications of the skeletal troponin $\mathrm{T}$ molecule during the purification procedures increase the "stickiness" of this protein. In the present study as in a previous one, ${ }^{19}$ there was no circulating troponin $\mathrm{T}$ in patients who had thoracic surgery only. This contrasts with the results for total creatine kinase and its $\mathrm{MB}$ isoform. Circulating cardiac troponin $\mathrm{T}$, however, was found in all patients undergoing cardiac surgery on extracorporeal perfusion, indicating some myocardial cell damage in all of them.

After reperfusion in patients with acute myocardial infarction the release kinetics of serum troponin $T$ resembled those of both structurally bound and cytosolic free proteins. ${ }^{26}{ }^{27}$ These release kinetics result from the intracellular compartmentalisation of troponin $T$, which is mostly bound to the contractile apparatus with only a small fraction in the cytosolic pool. ${ }^{27}$ The increase in serum troponin $\mathrm{T}$ concentrations one day after surgery which we found in the present study in all patients with cardiac surgery may result from release of the cytosolic pool of troponin $T$. Two of the 56 patients who had a short period of cardiac arrest and no electrocardiographic changes had only this early troponin $T$ release, which probably reflects minor and reversible ischaemic damage to the myocardial cell. In the remaining 49 patients undergoing cardiac surgery with longer periods of cardiac arrest and in the five patients with perioperative acute myocardial infarction there was a more long lasting increase (peak 2) in the serum concentrations of troponin $\mathrm{T}$. Because the serum half life of troponin $T$ is 120 minutes, the raised serum concentrations are likely to be the result of the continuing release of troponin $T$ from the disintegrating contractile apparatus. This degradation of myofilaments most probably indicates irreversible cell damage, which may be diffusely distributed throughout the myocardium. Hence, in patients with a prolonged increase in serum troponin $T$ the electrocardiogram showed non-specific changes rather than signs of myocardial infarction.

Diffuse myocardial cell necrosis after cardiac surgery was mainly encountered in patients with long lasting ischaemic cardiac arrest without cardioplegia. Despite excellent operative results these patients had severe left and even right ventricular pump failure. In our patients in whom cardioplegic solution and hypothermia were used for cardioprotection, cardiac ischaemia was well within experimentally determined periods of tolerance. ${ }^{28}$ Yet, despite this good cardioprotection many patients showed evidence of persistent troponin $T$ release. Thus under clinical conditions the tolerable ischaemic period may be shorter than forecast experimentally. This may be because the cardioplegic solution is unevenly distributed, or rapidly washed out from coronary circulation, or both.

In summary, the concentration of cardiac troponin $\mathrm{T}$ in serum can be used to identify and measure perioperative myocardial cell damage and may be useful in assessing the efficiency of 


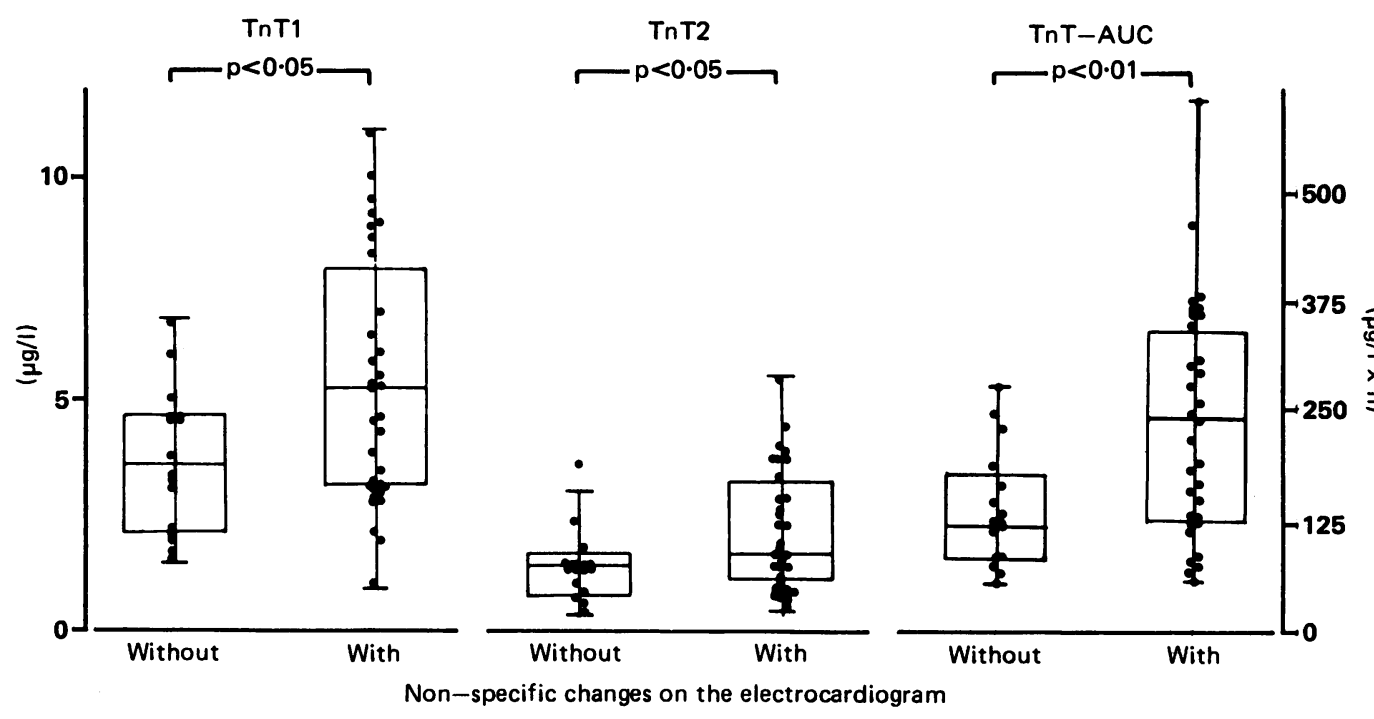

Figure 5 Changes on the electrocardiogram and in troponin $T$ release in patients who had cardiac surgery. Nonspecific changes on the electrocardiogram such as $S T$ segment and $T$ wave changes were more common in patients with increased early, late, and total troponin $T$ release. Patients with perioperative acute myocardial infarction are excluded. TnT1, troponin $T$ peak value on day 1 after operation; TnT2, troponin $T$ peak value on day 4 after operation; TnT-AUC, cumulative release of troponin $T$ calculated as area under troponin $T$ serum curve.

cardioprotective measures. The persistent increase in troponin $\mathrm{T}$ found in some patients who had cardiac surgery suggests that cardioplegia cannot prevent ischaemic cell damage during long periods of cardiac arrest. Thus under clinical conditions the ischaemic period that can be tolerated by the myocardium may be shorter than studies on isolated hearts indicate.

This study was supported by grants from the Deutsche Forschungsgemeinschaft, Bonn-Bad-Godesberg and from the Bundesministerium fuer Forschung und Technologie, Bonn.

1 Baldermann SC, Bhayana JN, Steinbach JJ. Perioperative myocardial infarction: a diagnostic dilemma. Ann Thorac Surg 1980;30:370-7.

2 Aintablian A, Hamby RI, Hoffmann I, Weisz D, Voleti C, Wisoff BG. Significance of new $Q$ waves after bypass grafting: correlations between graft patency, ventriculogram, and surgical venting technique. Am Heart $J$ 1978;95:429-40.

3 Fennell WH, Chua KG, Cohen L, et al. Detection, prediction, and significance of perioperative myocardial infarction following aorto-coronary bypass. J Thorac Cardiovasc Surg 1979;78:244-53.

4 McGregor CGA, Muir AL, Smith AF. Myocardial infarction related to coronary artery bypass graft surgery. $\mathrm{Br}$ Heart $J$ 1984;51:399-406.

5 Wagner GS, Roe CR, Limbird LE, Rosati RA, Wallace AG. The importance of identification of the myocardial specific isoenzyme of creatine phosphokinase ( $\mathrm{MB}$ form) in the diagnosis of acute myocardial infarction. Circulation diagnosis of acut

6 Jockers-Wretou E, Pfleiderer G. Quantitation of creatine kinase in human tissue and sera by an immunological kinase in human tissue and sera by an
method. Clin Chim Acta 1975;58:223-9.

7 Grande P, Christiansen C, Pedersen A, Christensen MS. Optimal diagnosis in acute myocardial infarction. A costeftectiveness study, Circulation 1980;61:723-8.

8 Str $\phi \mathrm{m} \mathrm{S}$, Bendz R, Olin C, Lundberg S. Serum enzymes with special reference to $\mathrm{CK}-\mathrm{MB}$ following coronary bypass surgery. Scand J Thorac Cardiovasc Surg 1979;13:53-9.

9 Rao PS, Brocks FE, Cleary K, Mueller H, Barner HB. Effect of intraoperative propranolol on serum creatine kinase $M B$ release in patients having elective cardiac operations. $J$ Thorac Cardiovas Surg 1984;88:564-6.

10 Wilkinson JM, Grand RJA. Comparison of amino acid sequence of troponin I from different striated muscles. Nature 1987;271:31-5.

11 Pearlstone JR, Carpenter MR, Smilie LB. Amino acid sequence of rabbit
12 Hoh JFY, McGrath PA, Hale PT. Electrophoretic analysis of multiple forms of rat cardiac myosin: effects of hypophysectomy and thyroxine replacement. J Mol Cell Cardiol 1978;10:1076-82.

13 Katus HA, Yasuda T, Gold HK, et al. Diagnosis of acute myocardial infarction: detection of circulating cardiac myocardial infarction: detection of circulating cardi

14 Cummins B, Auckland ML, Cummins P. Cardiac-specific troponin I radioimmunoassay in the diagnosis of acut myocardial infarction. Am Heart J 1987;113:1333-44.

15 Leger JOC, Bouvagnet T, Pau B, Roncucci R, Leger JJ. Levels of ventricular myosin fragments in human sera after myocardial infarction, determined with monoclonal antibodies to myosin heavy chains. Eur J Clin Invest 1985;15:422-9.

16 Katus HA, Diederich KW, Hoberg E, Kübler W. Circulating cardiac myosin light chains in patients with angina a rest: identification of a high risk subgroup. J Am Coll Cardiol 1988;11:487-93.

17 Katus HA, Remppis A, Looser S, Hallermeier K, Scheffold $T$, Kübler W. Enzyme-linked immunoassay of cardiac troponin $\mathrm{T}$ for the detection of acute myocardial infarction in patients. J Mol Cell Cardiol 1989;21:1349-53.

18 Gebhard MM, Bretschneider HJ, Gersing E, Preusse CJ, Schnabel PA, Ulbricht LJ. Calcium-free cardioplegia. Eur Heart J 1983;4:151-60.

19 Katus HA, Remppis A, Neumann FJ, et al. Diagnostic efficiency of troponin $T$ measurements in acute myocardial infarction. Circulation (in press)

20 Würzburg K, Hennrich N, Lang H, Prellwitz W, Neumeier $\mathrm{D}$, Knedel M. Bestimmung der Aktivitat von CK-MB im Serum unter Verwendung inhibierender Antikorper. Klin Wochenschr 1976;54:357-60.

21 Bulkley BH, Hutchins GM. Myocardial consequences of coronary artery bypass grafting. Circulation 1977;56: 906-13.

22 Seguin J, Saussine M, Ferriere M, et al. Comparison of myoglobin and creatine kinase MB levels in the evaluation of myocardial injury after cardiac operation. $J$ Thorac Cardiovasc Surg 1988;95:294-7.

23 Sobel BE, Roberts $R$, Larson KB. Considerations in the use of biochemical markers of ischemic injury. Circulation 1976;38:101-6.

24 Miyazawa K, Fukuyama H, Yamaguchi I, Kobayashi M, Washio M, Oda J. Serial determinations of serum enzymes following aorta-coronary bypass surgery and acute following aorta-coronary bypass surgery and

25 Piper HM, Schwartz $P$, Hütter JF, Spieckermann PG. Energy metabolism and enzyme release of cultured adult rat heart muscle cells during anoxia. J Moll Cell Cardiol 1984;16:995-1007.

26 Katus HA, Diederich KW, Schwarz F, Uellner M, Scheffold $T, K u ̈ b l e r ~ W$. Influence of reperfusion on serum concen trations of cytosolic creatine kinase and structural myosin light chains in acute myocardial infarction. $\mathrm{Am} \mathrm{J} \mathrm{Cardiol}$ $1987 ; 60: 440-5$.

27 Katus HA, Remppis A, Diederich KW, Scheffold T, Kübler W. Serum concentration changes of cardiac troponin $T$ in patients with reperfused and non-reperfused myocardial infarction. Am J Cardiol (in press).

28 Bretschneider HJ, Castaneda A, Denck H. Myocardia protection. J Thorac Cardiovasc Surg 1980;28:295-302. 